\title{
Research on Cost Control in Design Stage of Real Estate Development Project
}

\author{
Teng Li ${ }^{1}$, Shixia Duan ${ }^{1}$ \\ ${ }^{1}$ Management Engineering College, Zhengzhou University, Zhengzhou, China \\ 1004830383@qq.com,duanshixia@zzu.edu.cn
}

Keywords: real estate development project; design stage; cost control; value engineering

\begin{abstract}
Now the real estate market is facing challenges in the purchase of the policy of the tsunami and the development costs. As land prices have risen sharply, it is urgent for real estate development enterprises in such a harsh market situation to survive and develop. Most of the research results show that the design stage is the largest and most effective stage of the cost plasticity of the real estate development project. Therefore, it is of great significance to analyze the cost control measures in the design stage and provide the theoretical guidance for the real estate development enterprises. Against the development background of today's real estate industry, through the analysis of real estate development costs, this paper mainly discusses how to use the value engineering to optimize the design of the design scheme to ensure the better control cost under the premise of ensuring the quality of the design. This paper, by using the combination of qualitative and quantitative methods and theoretical and empirical methods, hopes to gain a scientific and comprehensive control of costs.
\end{abstract}

\section{Introduction}

With the advance of urbanization, "real estate" has gradually become a hot topic of public gossip, triggering the widespread concern of the whole society. On the one hand, house prices soared, on the other hand, the real estate market is facing the status of oversupply. As a real estate developer, in order to achieve business goals in the harsh market competition, it is necessary from the previous extensive business model into an intensive business model, cost control work is important, a direct impact on the entire project economic and market competition force. And the traditional cost control work will focus on the construction stage, attention to control and ex post control, often overlooked the most potential of the prior control, the data show that the project design costs accounted for a small proportion, but the whole The impact of the project cost can reach more than $80 \%$.

There has been considerable research on the cost control in the real estate design phase. Some scholars focus on the importance of cost control in the design phase. Real estate development enterprises to control the cost of the project, we must pay attention to the design stage of the work, from the beginning of the formation of strict control of the cost (Tao Lin, 2009); architectural design is the source of the project, architectural design, scientific and economic The key to determining the cost of the whole project plays a decisive role in the quality of the whole project. This is not only related to the daily operation of the construction project, but also to the safety of the construction and even the safety of the people (Lixia Ding, 2017). (Haiyan Li, 2015); and some scholars through the application of the quota design in the design of the construction stage analysis, pointed out that the cost of the design process cost control process exists in the process of the cost of the design of the cost of the design process (Xiaokai Lin, 2016); more articles put forward the value of engineering applications in the limit design, and to do this in-depth study, given the specific steps (Pengfei Li 2015).

Based on the overview of real estate development cost, this paper summarizes the previous research results by consulting a large number of literatures. First, it analyzes the important position of cost control in the design stage, and finds that the cost control effect is not ideal at the present stage. Then, the paper analyzes the factors that affect the cost control effect from the macroscopic 
point of view. First, the traditional cost control measures such as the application of the quota design itself are many, and the second is the phenomenon that the design quality is low leads to the design change and rework. The finally, combining with the application of new technology in the information age, this paper puts forward a series of methods to solve the problem of cost control, and analyzes and applies the value engineering in order to improve the level of cost control of real estate development projects, so as to bring more real estate enterprises more good economic benefits.

\section{Analysis on the current situation of cost control in the design stage of real estate development project}

\subsection{The importance analysis of cost control in design stage}

Design cost impact is first reflected in the design of a direct impact on the construction project investment, the correct and reasonable program design can greatly reduce the amount of engineering, improve project quality, save investment. Second, the preliminary design stage is based on the design of the program to further improve the cost control is an important part of the project cost and reduce the use of the project after the operation cost has an important impact. If the design quality is rough, the missing item or the design depth can not meet the requirements of the national standard, it is difficult to control the project cost at the construction stage, resulting in the additional cost and the delay of the construction period (Lixia Ding, 2017). Figure 1 shows the impact of the cost of each stage of the project life cycle.

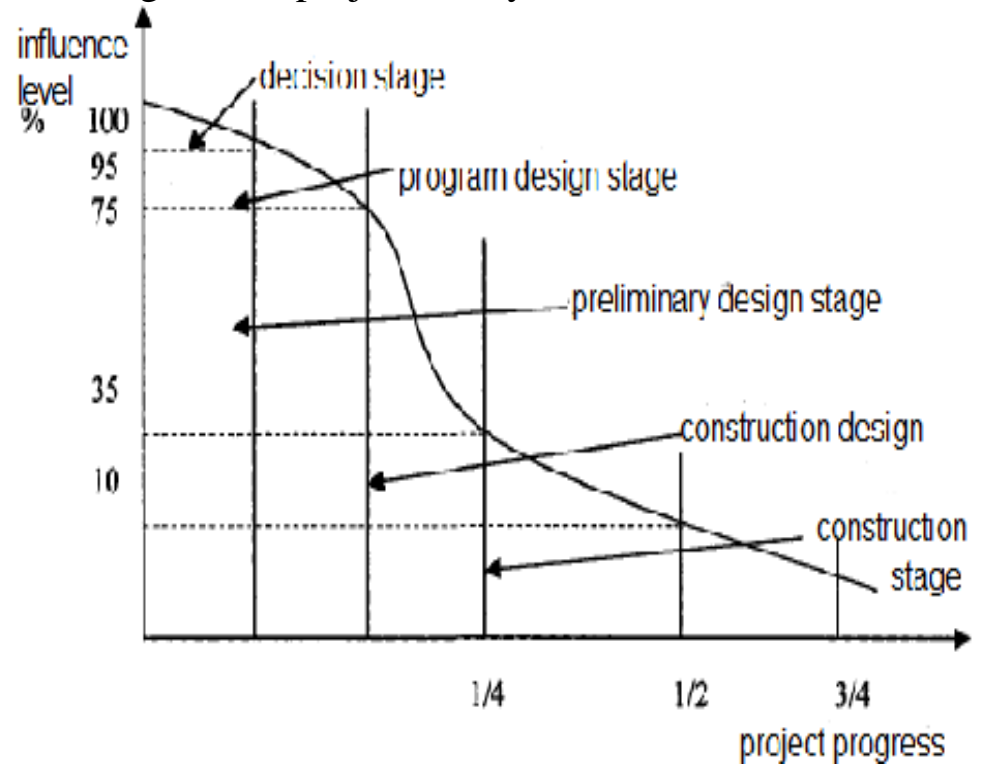

Figure1: shows the impact of each stage on the cost of the curve.

From the graph can be seen that despite the design costs are negligible, but the impact of the cost of the entire project as high as $80 \%$ or more, "pen under a line, spend tens of millions of investment" is the design stage of the investment has a significant impact on the image (Shi Qiu, 2014).

\subsection{Design of traditional cost control theory in design stage}

At present, the real estate enterprises in the design stage of the cost control of the most important tool is the limit design. The so-called quota design, that is, in accordance with the approved design task book and investment estimation and control of the initial design, in accordance with the preliminary design of the total cost control design drawings, while the professional to ensure the use of the function under the premise of the allocation of investment limit control design, Technical design and construction drawings in the design of unreasonable changes to ensure that the total investment limit is not a breakthrough (Jingjuan Guo,2010).

At present, including the limit design, program selection and value engineering, including the traditional cost control methods, the application alone can not meet the pursuit of quality for the 
enterprise's core competitiveness of real estate development enterprises on the need for cost control, as the reasons for the following do detailed analysis.

\section{An analysis of the causes of cost control effect in design stage}

The cost of real estate development is complicated, and the factors influencing the cost are many. Therefore, the reason of the poor cost control is also multifaceted. This paper summarizes the following two main factors based on the research focus.

\subsection{Limit design in the design stage cost control has limitations}

\subsubsection{Project function does not match cost}

In the actual project, it is often too much emphasis on the importance of investment limits, trade-offs, focus on the completion of investment control tasks, but ignore the requirements of the project quality, rather than focus on the function and cost of unity, resulting in the project function and cost mismatch.

\subsubsection{Lack of scientific indicators}

Some of the investment limits are put forward according to the conceptual design. There are also projects which are based on the experience of the project. No comparative analysis of the multi-scheme is carried out. The final investment limit may not be scientific and the investment should be used as the requirement of quota design. In this case, it will bring great difficulties to the design of the quota. Under the unreasonable limit, the design can not meet the required functional quality requirements, which will eventually lead to project investment or exceeding the quota requirement, or reduce the design standard.

\subsection{Design quality defects lead to uncontrolled costs}

With the development of the times, the progress of science and technology, the drawbacks of the traditional design methods are more and more, the design quality defects are often exposed in the construction phase, resulting in design changes and rework, making Jian'an cost greatly increased, and design quality is generally low The main reason is because the design cycle is unreasonable, the lack of coordination of traditional design methods, the traditional design project is not clear and so on several aspects caused by the effect.

\section{Measures to improve the effectiveness of cost control in the design phase}

By examining a large number of documents, we can see that there are many ways to cost control in the design stage today, such as the use of value engineering to optimize the design phase of the project to improve the limit design to control the cost; to implement the standardized design to ensure the design quality, technological innovation to improve the design quality ; combined with the development prospects of the times, in the design stage using BIM information collection technology to implement cost control. In this paper, the combination of qualitative and quantitative, theoretical and empirical combination of the way, mainly on the use of value engineering program to improve the limit design to control the cost to illustrate.

\subsection{Based on the value of the design of the project to improve the optimal design}

\subsubsection{Value Engineering Overview}

(1)Value Engineering Theory and Its Application

Value engineering is a modern science and technology that is closely integrated with technology and economy. Value is the ratio of the cost of evaluating a project and the cost of implementing this function. It is expressed as: $\mathrm{V}=\mathrm{F} / \mathrm{C}$ (where $\mathrm{V}$ is the value coefficient and $\mathrm{F}$ is the functional coefficient $\mathrm{C}$ ). The use of value engineering theory to control the investment limit of the project, according to the function of investment distribution, inspiration we focus on the value coefficient, to seek a balance between cost and function, to maximize the value of the project.

(2)The existence of the value of the best

The existence of optimal value is illustrated by the relationship between life cycle cost and project function (Figure 2). Where: $\mathrm{C}=\mathrm{Cm}+\mathrm{Cn}$, (FO, CO) is the best value. The purpose of this method is to make the proportion of the cost allocated to each component close to the proportion of 
its function, ie $\mathrm{V}=\mathrm{F} / \mathrm{C}$ is approximately equal to one. It can also be said that the method is determined by the functional relationship between the various components of the project itself to determine the design limit, a greater degree of investment to achieve the rationality of the proportion.

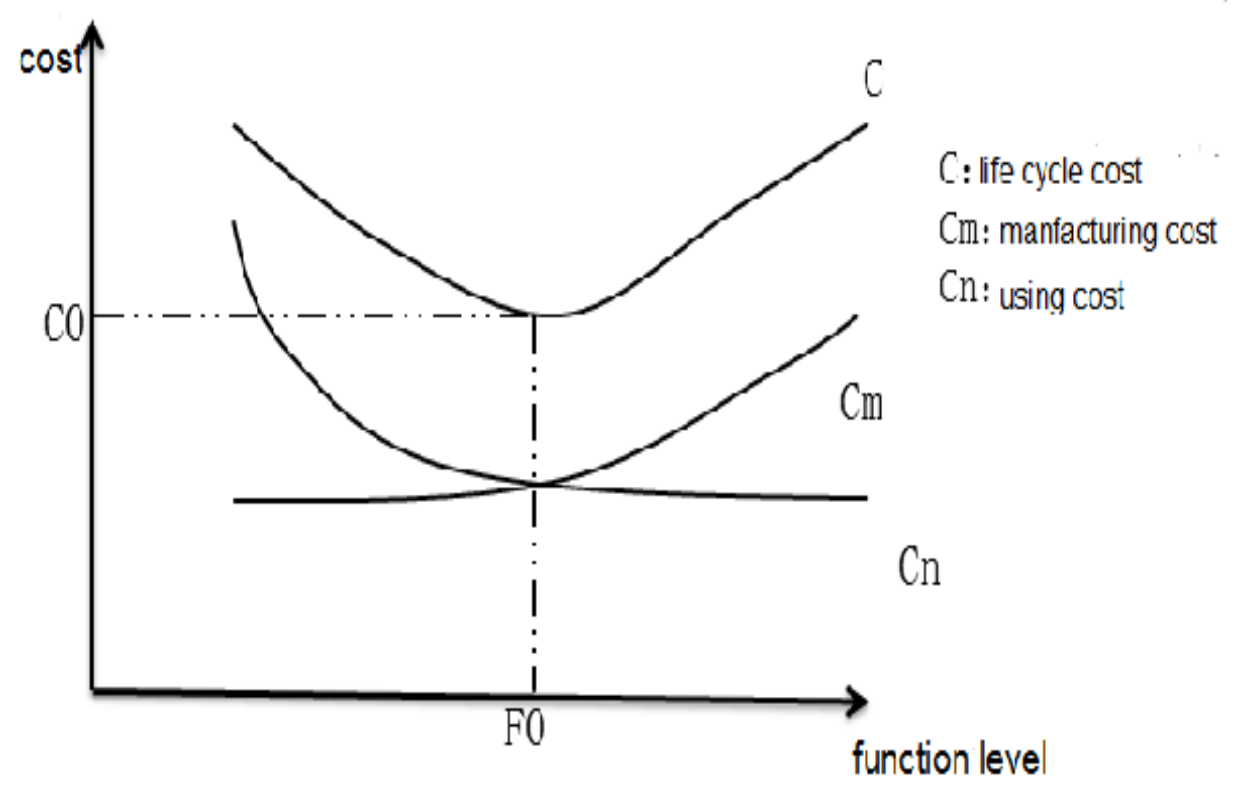

Figure2:The relationship between the life cycle cost and the functional level

\subsubsection{Utilize value engineering for design stage optimization}

A real estate project can meet the requirements of the owners and customers a lot of the program, the design of the program directly affect the results of a comprehensive investment project results, resulting in functional and cost differences. First of all, systematically consider the social, technical and economic characteristics of real estate project design, establish a comprehensive system design evaluation index system, including functional index system and cost index system, taking into account the fuzzy characteristics of the program optimization, make full use of expert experience, reasonably determine the weight of each evaluation index and the rating of each program. The function index and the cost index of the scheme are obtained, and the value index is obtained, and the optimal scheme is obtained according to the value engineering principle according to the value engineering principle.

The use of value engineering method for the design of the preferred steps are generally:

(1) Functional analysis

Functional analysis is the value of engineering staff design, construction and construction units of the relevant personnel to discuss the various functions of the residential to define, organize and evaluate the analysis. Combined with the design, the construction unit of the views of a comprehensive score, the user, design and construction units to consider the three views and determine the weight.

The function of real estate products are generally divided into social function, applicability function, technical function, physical function and aesthetic function. Functional analysis should first clear what specific functions of the project, which is the main function, and the function of the definition and finishing.

(2) functional evaluation

Functional evaluation is mainly to compare the importance of the function, the current function of the weight of the weight is generally determined by expert scoring method.

(3) cost coefficient CI calculation formula is as follows:

$C I=\frac{\text { The cost of a square meter }}{\text { The sum of all the options for the square meter }}$

(4) The function evaluation coefficient FI is calculated as follows: 
$F I=\frac{\text { A program satisfies the total score }}{\text { All selection programs meet the total score }}$

(5)The value coefficient VI is obtained and the evaluation is carried out

According to the formula VI = FI / CI, the value coefficients of each scheme are obtained respectively. Considering all the factors, the scheme with the highest value coefficient is the optimal scheme.

\subsection{Example application}

Taking the project of Heilongjiang water conservancy scientific research complex as an example to illustrate the application of value engineering in the design stage cost control.

\subsubsection{Project Background}

The nature of the project for the public buildings, construction land area of 32,600 square meters, on behalf of the road land area of 5900 square meters. Planning the total floor area of 18,800 square meters, roads, parking area of 7100 square meters, the total green area of 10200 square meters, green rate of $31 \%$, planning volume rate of 0.6 , control $70 \mathrm{~m}$ high. The main part of the project on the ground 18 layers, local 17 layer. Seismic fortification category for the B class, seismic fortification intensity of 6 degrees, the structure of the framework for the shear wall structure, shear wall seismic rating of four.

\subsubsection{Application of value engineering to optimize the design}

(1) Functional evaluation analysis

First of all, according to the "applicable, economic, safe, beautiful" principle for the definition of the function of the building, after the investigation of the project and related information on the sub-item, the specific function is now broken down into five functions and 10 sub-functions, and Its function evaluation analysis, as shown in the table. In the table, the weight of each function is taken into consideration, and the weight of the three parties is calculated by the users, designers and construction workers (the weights of the three are set to 0.5,0.3,0,2)respectively.And then obtain the weighted score of each program, and then calculate the functional coefficient of each program. See Table 1.

(2)Cost factor calculation

The cost factor for each program is based on the estimated cost of the design of each scenario, as shown in Table 2.

(3)Calculate the value coefficient

Calculate the value coefficients for each scheme according to VI = FI / CI, as shown in Table 3.

(4) Program evaluation and selection

From Table 3, we can see that the value coefficient VI $<1$, the value coefficient $\mathrm{VI}>1$ of scheme $\mathrm{B}$ and $C$ and the value coefficient of scheme $B$ and $C$ are very small, and the cost coefficient of scheme $\mathrm{C}$ is obviously smaller than that of scheme A Cost factor, ie the lowest cost. In other words, program $\mathrm{C}$ is not only low cost and high value coefficient, the lowest cost to obtain the best quality of real estate projects. Considering all aspects of the consideration, choose option C.

\section{Conclusions}

The paper analyzes the importance of cost control in the design stage, that is, the "cost control is focused on the design". The factors influencing the cost control effect are analyzed in detail: the typical cost control theory, Such as because the limit design too much emphasis on "quota" to extend the design cycle, limiting innovation led to its practical application of the increase in costs, it is proposed in the value of the project based on the improvement of the limit design; On the basis of value engineering design optimization. And in the final use of examples of proof of the way the use of the method in practice to illustrate. In order to realize the effective cost control in the design stage of the real estate development project, the engineering designer should fully understand the importance of the cost control in the design stage, understand the meaning of the value engineering, systematically study the value engineering and cost control knowledge, make full use of the value engineering Method combined with the specific situation of real estate development projects, in the 
design stage of scientific and effective design optimization, so as to effectively control the project cost, to achieve the function and cost of harmonization. Due to limited knowledge, some analysis of the article is not enough in place, the views are not deep enough. For example, due to the current situation of the current situation of the cost control research in the design stage of the real estate development project, the cost control of the value engineering is still relatively small, the method of cost control in the design stage and the model has certain limitations, and the cost control of the real estate project in the design stage, requires a deeper level of research.

Table1. Functional evaluation coefficient calculation

\begin{tabular}{|c|c|c|c|c|c|c|c|}
\hline \multirow{2}{*}{$\begin{array}{l}\text { function } \\
\text { name }\end{array}$} & \multirow{2}{*}{$\begin{array}{l}\text { user } \\
\text { staff } \\
\text { score } \\
\text { F1 }\end{array}$} & \multicolumn{2}{|c|}{ design construction } & \multirow{2}{*}{ Importance weight } & \multirow[b]{2}{*}{$A$} & \multicolumn{2}{|c|}{ Program } \\
\hline & & $\begin{array}{l}\text { staff }= \\
\text { score } \\
\text { F2 }\end{array}$ & $\begin{array}{l}\text { staff } \\
\text { score } \\
\text { F3 }\end{array}$ & & & B & c \\
\hline flat lay out & 32 & 28 & 27 & 0.298 & 10 & 10 & s \\
\hline \multicolumn{8}{|l|}{ lighting and } \\
\hline ventilation & 16 & 15 & 16 & 0.157 & 10 & 10 & s \\
\hline \multicolumn{8}{|l|}{ solid and } \\
\hline durable & 21 & 15 & 20 & 0.19 & 10 & 10 & 10 \\
\hline three precautions & 5 & 5 & 4 & 0.048 & $\mathbf{s}$ & 6 & 6 \\
\hline \multicolumn{8}{|l|}{ architectural } \\
\hline modeling & 2 & 6 & 3 & 0.034 & 10 & 10 & s \\
\hline \multicolumn{8}{|l|}{ inside and outside } \\
\hline decoration & 6 & 7 & 6 & 0.063 & 6 & s & 5 \\
\hline \multicolumn{8}{|l|}{ coordination with } \\
\hline land occupation & on 4 & 6 & 5 & 0.048 & 8 & 8 & 8 \\
\hline \multicolumn{8}{|c|}{ coordination with the } \\
\hline environment & 5 & 6 & 3 & 0.049 & 8 & 6 & 6 \\
\hline \multicolumn{8}{|l|}{ economy and } \\
\hline energy saving & 4 & 5 & 9 & 0.053 & 7 & 5 & 8 \\
\hline \multicolumn{8}{|l|}{ environment } \\
\hline friendly & 5 & 7 & 7 & 0.06 & 10 & 10 & 8 \\
\hline total & 100 & 100 & 100 & 1 & 9.299 & 9.125 & 8.094 \\
\hline functional coefficie & ent & & & & 0.351 & 0.344 & 0.30 \\
\hline
\end{tabular}


Table 2 .project option cost cactor calculation

\begin{tabular}{|c|c|c|c|}
\hline $\begin{array}{l}\text { program } \\
\text { factor }\end{array}$ & key features & pected construction cost yuan $n^{2}$ & cost \\
\hline A & $\begin{array}{l}\text { Layer height } 3.2 \mathrm{~m} \text {, the structure } \\
\text { of the program for the steel frame, reinforced } \\
\text { silicon bearing wall, outside wall for the addition } \\
\text { of silicon block, partition wall for the light steel keel } \\
\text { gypsum board wall, area utilization factor is } 0.93 \text {, } \\
\text { pouring pile foundation, with underground garage. }\end{array}$ & 1570 & 0.371 \\
\hline B & $\begin{array}{l}\text { Layer height } 3.2 \mathrm{~m} \text {, the structure of the program } \\
\text { or the frame shear structure, wall materials used } \\
\text { more hole brick and mobile detachable partition, } \\
\text { the area utilization factor is } 0.89 \text {, prefabricated pile } \\
\text { foundation with underground garage. }\end{array}$ & 1400 & 0.331 \\
\hline $\mathrm{C}$ & $\begin{array}{l}\text { Layer height } 3.2 \mathrm{~m} \text {, the use of brick and } \\
\text { concrete structure, wall materials using standards clay } \\
\text { brick. area utilization factor } 0.7 \text {, prefabricated pile } \\
\text { foundation, with underground garage. }\end{array}$ & 1260 & 0.298 \\
\hline
\end{tabular}

Table 3 .The value of the three alternatives

\begin{tabular}{|cccc|}
\hline Program & A & B & C \\
\hline Value factor & 0.946 & 1.03 & 1.02 \\
\hline
\end{tabular}

\section{References}

[1] Baikun Yang, D.,2008. Research on cost control of real estate development project design stage based on value engineering, Northeastem University.

[2] Haiyan Li, D., 2015. BIM - based real estate project design stage cost control research, Tianjin University.

[3] Huiwan Cai, Li Tao, 2012. Discussion on project cost control under quota design, Construction Economics. (2), pp.44-46.

[4] Jingjuan Guo, M., 2010. Project cost management, Beijing, Tsinghua University press.

[5] Lixia Ding ,2017. The Importance of cost control in design stage, Residential and real estate. (5), pp.26-27.

[6] Pengfei Li, D, 2014. Value engineering in the construction project limit design application, Chinese academy of sciences.

[7] Shi Qiu, 2014. How to do cost control at the source of cost., Residential and real estate. (6), pp.25-26. 
[8] Tao Lin, 2009. Real estate development and design stage of the cost control, Shanxi architecture. (28), pp.232-233.

[9] Xiaokai Lin, 2016. Application of quota design in the design stage of building engineering, Building materials and decoration. (49),pp.69-70 